\title{
A DYNAMIC ANALYSIS OF NET MIGRATION AND STATE EMPLOYMENT CHANGE
}

\author{
John S. Gruidl and Glen C. Pulver*
}

\begin{abstract}
The dynamic relationship of net migration and employment change is examined for ten selected states of the U.S. using a multivariate time series approach - a vector autoregression (VAR) model. Granger causality tests and dynamic multipliers provide information on the dynamic process. The results suggest a state-level process in which employment change occurs first, and net migration follows with a lag. The procedure appears promising in investigating the timing of net migration and regional employment change.
\end{abstract}

\section{INTRODUCTION}

In recent decades the U.S. economy has been characterized by regional shifts in population and in employment. In the decade of the 1970's, $89.9 \%$ of the nation's incremental population and $72.5 \%$ of incremental nonagricultural employment was captured by the South and West Census regions [Greenwood (1985)]. In the 1980's, the South and West continued their gains, receiving $89.2 \%$ of the increase in the nation's population and $66.4 \%$ of incremental nonagricultural employment in the period 1980-87 [U.S. Bureau of the Census (1988, 1989)].

The pattern of regional shifts seems to change over time. For example, changes in the patterns of population shifts occurred in the early 1980's [Rogerson and Plane (1985)]. The Northeast experienced positive net migration in 1983 for the first time since 1970. Rogerson and Plane (1985) also found that "although the West still has more in-migrants than out-migrants, the difference is declining" (p.47).

The patterns of regional shifts in population and employment are poorly understood. It seems unlikely that regional population changes, brought about by net migration, and employment changes are independent events; more likely they relate and possibly interact. The objective of this research is to examine the relationship between net migration and regional employment over time. The questions addressed are: (1) does net migration respond to employment change, and if so, what is the timing and magnitude of the response; (2) does employment

\footnotetext{
*The authors are respectively, Research Associate, Institute for Rural Affairs, Westem Illinois University, and Professor, Department of Agricultural Economics, University of Wisconsin Madison. Helpful suggestions on earlier drafts were given by Jean Paul Chavas, Brian Gould, Raja Velu, and three anonymous referees.
} 
change respond to net migration, and if so, what is the timing and magnitude of the response; and (3) which of these responses is dominant?

Previous studies [e.g., Greenwood and Hunt (1984)] have focused on the magnitudes of the relation between net migration and employment. The procedure used in this study enables investigation of the timing of net migration and employment change, i.e., the extent to which net migration leads, lags, or occurs simultaneously with employment change.

This research employs a multivariate time series approach, in particular a vector autoregression model, to examine the dynamics of net migration and regional employment change in ten selected states for the period 1951-85. Granger causality testing and dynamic multipliers are used to provide additional information about the timing and magnitudes of net migration and employment change.

An understanding of the migration-employment linkage may provide insight into the mechanics of regional economic growth and decline. Furthermore, understanding the dynamic process of net migration and employment change may aid in the selection of regional development policies.

Six sections follow: a review of previous research on the net migrationemployment relation, the presentation of the empirical model, a discussion of Granger causality testing and dynamic multipliers, a brief description of the data, the results of the empirical estimation, and further analysis and summary.

\section{PREVIOUS STUDIES}

The relationship between regional changes in net migration and employment has been the subject of considerable research. Muth (1971), Greenwood and Hunt (1984), and Greenwood, Hunt, and McDowell (1986) considered the relation between net employed migrants and employment change in urban areas using simultaneous equation models. Their objective was to estimate the magnitudes of: (1) net migration's response to employment change, and (2) employment's response to net migration.

Muth (1971) studied the relation in a cross-section model with 1950-60 Census data. He developed a two-equation econometric model using the rate of change of net migration and the rate of employment change as dependent variables. Muth found that: (1) net in-migration resulted in a direct increase in employment that was approximately equal to the number of in-migrants who entered the labor force and (2) employment growth attracted migrants, though the effect was not quite as large. Muth (p. 295) concluded that "migration and employment growth each affect and are affected by the other." 
Greenwood and Hunt (1984) present one of the few dynamic models of migration and regional employment in the U.S. using time-series data from the Continuous Work History Survey to estimate a simultaneous equation model. They argued that in-migrants could cause a shift in the regional labor demand schedule. Migrants may bring changed demand for regional goods and services. The demand change may influence the profitability of regionally produced goods and services and therefore affect product and labor demand. If migrants cause a shift in the labor demand schedule, migration would cause an increase in employment greater than the migrant's own employment.

The Greenwood and Hunt model consisted of three behavioral equations with dependent variables of net migration, employment change, and earnings change. The model had a dynamic structure because of the inclusion of a lagged dependent variable as an explanatory variable in each behavioral equation. Generally, the Greenwood and Hunt results were similar to those of Muth.

Greenwood, Hunt, and McDowell (1986) also used the Continuous Work History Survey data, although they took a cross-section perspective by estimating the model for each of 17 years, 1958-75. The simultaneous equations model for each year consisted of three behavioral equations with dependent variables of rate of change of net migration of employed persons, rate of employment change, and rate of change of average annual earnings. Each equation included a lagged dependent variable.

Greenwood, Hunt, and McDowell (1986) found a temporal pattem in the relation of net migration and regional employment. Migrants had a smaller impact in inducing job creation during expansionary periods. In addition, "the migrant attractive power of another job rises during national upswings and falls during downswings" (p.223).

Schmitz (1986) used a time-series methodology to explore the relationship between net migration and employment in states from 1947-81. The variables of net migration, employment, manufacturing wage, and national output were included in an autoregressive model. Granger causality testing was applied after following a search technique using the Final Prediction Error (FPE) criterion to determine lag structure. The causality tests suggested a regional pattern. Migration driven states were more likely located in the South and West Census regions. Net migration responses to employment change were found to be slower than employment responses to net migration. 


\section{THE EMPIRICAL MODEL}

Migration is commonly viewed in a human capital framework as an investment decision (Sjaastad, 1962). It involves costs, but produces a future stream of benefits. A household will migrate if the expected present value of benefits is greater than the expected present value of costs.

The household will consider two types of benefits in the migration decision. First, moving may bring an improvement in earnings. Earnings in the potential destination regions are uncertain because the job availability and wage for a particular mix of human capital in a distant place are largely unknown. Second, the household also benefits from what Graves and Linneman (1979) termed nontradeable goods, those goods that are available only locally, such as climate, scenery, and personal safety. As Graves and Linneman stated, changed demand for non-tradeable goods can only be met by relocation.

Costs associated with migration include direct moving expenses, as well as loss of location-specific human capital (such as job seniority, vested retirement benefits, networks of friends and family). The value of lost location-specific human capital may be uncertain at the time the move is being considered.

A household considering migration may reduce the uncertainty of benefits and costs by searching out information on employment opportunities and wages in potential destination regions. Also, the household may gather information on location-specific human capital in order to evaluate the potential loss if the move is undertaken. This search process will take time, implying that households may respond slowly to changes in earnings opportunities in other regions and/or to changes in their demand for non-tradeable goods.

Regional flows of migrants have a role in the process by which regional labor markets adjust to changes in labor demand and supply. Two distinct scenarios for the relation of migration and employment in an adjustment process are considered. First, in-migration that is stimulated by factors unrelated to the labor market (e.g., changed demand for non-tradeable goods) may occur to a region. In-migration raises population levels, and may increase the supply of labor. The higher population may demand more of regionally produced goods and services, which will transmit to increased labor demand. With both the labor demand and supply curves shifting to the right, regional employment increases, although whether wages rise or fall depends on empirical factors. Under this scenario, migration influences employment. ${ }^{1}$

Under the second scenario, the adjustment process is initiated by regional labor demand or supply shifts (due to factors other than migration). If labor demand increases (due to say technological change or capital in-flow), employment and wages will increase. Assuming that employment and wage levels in 
other regions remain the same, the perceived earnings benefits will spur in-migration. This implies that employment influences migration.

Each of these possibilities imply a unidirectional relationship between net migration and regional employment change. Other scenarios can be devised in which the relationship would be bidirectional. In any case, there is no clear theoretical basis to determine the sequence of events and the degree to which migration or employment are exogenous. ${ }^{2}$

The labor market adjustment process is viewed as dynamic, as flows of migrants are not expected to occur in the same period as regional changes in employment and/or wages. Dynamics arise because households may respond slowly to employment and wage opportunities in other regions due to uncertainty and search behavior, or because employment creation may lag population increases.

To model the dynamic adjustment process of regional labor markets, a time series approach is employed. Sims (1980) suggested a strategy for modeling multiple time series when hypothesis testing is of primary importance. He proposed the estimation of unconstrained vector autoregression (VAR) models whose purpose is to capture regularities in the data.

Theoretical information is used only in stipulating the set of variables to be included in the VAR model. The model does not require that variables be categorized as endogenous or exogenous or that restrictions be imposed on the lead-lag structure. Instead, it is constructed by allowing all variables to influence all others with lags. Pretesting is used only to choose the lag length. All coefficients, whether significantly different from zero or not, are kept in the final model. A shortcoming of the VAR model is that it strains available degrees of freedom in a small sample. ${ }^{3}$

The variables included in the VAR model are the essential components of the regional labor market adjustment process: regional migration, wages, and employment. Also, a proxy variable representing the business cycle is included. ${ }^{4}$

(1) Net migration. The choice of net migration rather than gross migration is dictated by data limitations. However, net migration is consistent with the adjustment perspective of regional labor markets since the residual flow of migrants provides impetus for regional labor demand and supply changes.

(2) Relative wages. It is the level of wages relative to other regions, not the absolute level of wages, that is critical in affecting net migration.

(3) Employment. In several studies, regional employment growth has been found to be the most important factor affecting net migration [e.g., Gordon (1985) and Molho (1984)].

(4) Employment in all other regions. Greenwood, Hunt, and McDowell (1986) and Gordon (1985) found evidence of cyclical variability in the relation- 
ship of net migration and regional employment. During recessionary times, earnings in the potential destination region are more uncertain and, ceteris paribus, a household might be less likely to migrate. On the regional level, it is expected that flows of migrants will be less responsive to employment changes during recessionary periods. In this work, U.S. employment in all other regions is used as a crude cyclical indicator. Also, inclusion of this variable provides explicit control over employment changes in other regions.

The VAR model for each region can be developed in the following way. Define $Z_{t}$ as a four-component vector, $Z_{t}=\left(M_{t}, W_{t}, E_{t}, N_{t}\right)$, where $M$ is net migration, $\mathrm{W}$ is relative wages, $\mathrm{E}$ is employment (in that region), and $\mathrm{N}$ is employment in all other regions, at year t. Following Bessler (1984), if $Z_{t}$ is a covariance stationary stochastic process that is linear, it has an autoregressive (AR) representation, given in general as:

$$
Z_{t}-\emptyset_{1} Z_{t-1}-\emptyset_{2} Z_{t-2}-\ldots . .=u_{t}
$$

where $u_{t}$ is a white-noise error (innovation) vector, with contemporaneous covariance matrix, $\Sigma$, and where $\emptyset_{\mathrm{i}}, \mathrm{i}=1,2 \ldots . .$. are m-by-m matrices of autoregressive parameters.

Equation (1) relates the current value of the $Z$ vector to an infinite lag of its past values. In practice, lag length must be truncated to some number which is operationally calculable, yet yields residuals which are white noise. In this work, the number of lags, i.e., the order of the system, is allowed to vary from 1 to 4 , with the same number of lags used for each variable in every equation. The order selected minimizes Akaike's Information Criterion (AIC). ${ }^{5}$

The selected model is estimated by seemingly unrelated regression (SUR). SUR jointly considers all the equations, thus obtaining a gain in efficiency over least squares estimation. SUR estimates are asymptotically efficient if the true model is selected and the errors are not serially correlated.

Though model selection is based on AIC, diagnostic tests are also performed. In particular, the adequacy of the model is evaluated with the Ljung-Box Q-statistic which provides a test for general serial correlation of the residuals.

\section{PROCEDURE}

After estimating the VAR model, two operations are performed. First, Granger causality tests ascertain information about lag-lead relationships between net migration and employment. Second, dynamic multipliers provide evidence on 
the magnitude, direction, and timing of the relation between net migration and employment.

\section{Granger Causality}

Granger (1969) defined causality in terms of predictability. Under his definition " $X$ causes $Y$ " if the knowledge of past $X$ reduces the variance of errors in forecasting $Y_{t}$ beyond the variance of errors which would be made from knowledge of past $Y$ alone. Granger defined instantaneous causality as existing when current as well as past values of $X$ are used to predict $Y$. If $X$ causes $Y$ and $Y$ causes $X$, there is feedback between the two variables. If $Y$ does not cause $X$ and $X$ does not cause $Y$ (even instantaneously), the two series are unrelated.

Granger's definition of causality has been widely debated in the literature. This research follows Brorsen, Chavas, and Grant (1985, p. 365) who employ Granger causality tests "as tests of relative predictive efficiencies that are used to determine lag-lead relationships."

In a VAR model, Granger causality tests are operationalized by testing the restriction that a block of coefficients for the lags of a particular variable are equal to zero. For example, testing the null hypothesis that $X$ does not cause $Y$ is done by testing the restriction that the coefficients on the lagged values of $\mathrm{X}$ in the $\mathrm{Y}$ equation are equal to zero. Use of the Granger procedure is supported by Monte Carlo results [e.g., Guilkey and Salemi (1982)].

\section{Dynamic Multipliers}

Dynamic multipliers are defined as the change in the expected value of a variable from a shock in one of the variables, with the one-time random shock occurring via the error term. Dynamic multipliers are an effective technique to examine the magnitude, direction, and timing of the dynamic relationships in the VAR model. ${ }^{6}$

Two types of dynamic multipliers are used here; impulse responses and intermediate-run multipliers. Let $\mathrm{R}(\mathrm{i})_{\mathrm{YX}}$ denote the ith period impulse response of variable $Y$ to a one-time shock in variable $X$. $R(i)_{Y X}$ measures the expected change in $Y$ in time period $t+i$ in response to a one-unit shock in the orthogonalized error of $X$ at time $t$. The set of impulse responses simulates over time the response of that variable to a change in another (or the same) variable.

Intermediate-run multipliers are defined here as the standardized sum of impulse responses. In particular, denote the first period shock in $\mathrm{X}$ that gives rise to $Y$ 's impulse response as $S_{\mathbf{x}}$. $S_{\mathbf{X}}$ is equal to one-unit of $\mathbf{X}$ 's orthogonalized error. The intermediate-run multiplier [IRM(n)] which measures the expected change in 
the variable $\mathrm{Y}$ over $\mathrm{n}$ periods is defined as:

$$
\operatorname{IRM}(\mathrm{n})=\left(1 / \mathrm{S}_{\mathbf{x}}\right) \Sigma R(\mathrm{i})_{\mathrm{YX}}
$$

Intermediate-run multipliers are measured, in this study, at three and six years (i.e., $n=3,6)^{7}$

The impulse responses are also useful in measuring the timing of responses. The adjustment period [following Brorsen, Chavas, and Grant (1985)] is defined as the number of periods after the shock when the impulse response is last significantly different from zero.

\section{DATA DESCRIPTION}

The unit of observation used in this study is the state. ${ }^{8}$ To keep the data analysis manageable, ten states were selected. The migration/employment relation might be different in expanding versus declining economies. Therefore, states with varying patterns of employment growth were chosen, based on an examination of employment change in 48 states over sub-periods of the 1951-85 interval. Five categories of employment growth were developed. High growth states are represented by California and Colorado, accelerating growth states by New Hampshire and Washington, average growth states by Nebraska and Kansas, decelerating growth states by Maryland and Tennessee, and low growth states by New York and Illinois. The selected states represent all eight Bureau of Economic Analysis regions, except the Southwest.

Annual data on net migration, relative wages (average wages in the state relative to the national average wage), state employment, and other U.S. employment (i.e., employment in all other states) are used for these ten states over the period 1951-85.

Net migration is calculated as a residual: total estimated population change minus the difference between births and deaths. The migration data are of population migration, referring to movements of entire households, rather than movements of employed persons only. ${ }^{9}$

As with most economic time series, the levels in all variables (except for net migration) exhibited a rising trend. To detrend the data, first differences were taken of all variables except for net migration. The resulting time series were found to be covariance stationary. 


\section{RESULTS}

The empirical results are summarized in Granger-causality tests and dynamic multipliers. The evidence suggests that net migration does not influence employment change in the study states. However, employment change does influence net migration, with the response of net migration typically taking several years. The typical magnitude is 1 to 2 additional in-migrants (over a three-year period) for each new job. More specific results follow.

Four-variable VAR models were estimated for each of the study states. The models were checked for stability by examining impulse responses over 30 periods and were determined to be stable. Ordering of the variables in the VAR is necessary to calculate the dynamic multipliers. This ordering pertains only to the contemporaneous behavior of the variables. Ordering should be based upon a priori beliefs (or theoretical expectations) about the sequence of events. In the VAR models, other U.S. employment is placed first in the ordering because it is essentially a national variable, which would be expected to affect state variables, but not be affected by them. Net migration is placed last in the ordering, consistent with the Granger causality results (see below). Finally, relative wages are placed before state employment in the ordering, based on the findings of Sargent (1976) and Neftci (1978) that wages cause (in a Granger sense) employment in the U.S. The resulting ordering is other U.S. employment, relative wages, state employment, net migration.

The models selected (i.e., those that minimize Akaike's Information Criterion) are auto-regressive $\operatorname{AR}(1), \operatorname{AR}(2)$, or $\operatorname{AR}(3)$. For all models, the value of the Ljung-Box Q-statistic for each equation is less than the chi-square critical value at the 5\% significance level. Thus the null hypothesis that the residuals are white noise cannot be rejected for any equation in any of the models. These tests suggest that the order of the models is sufficient to capture the regularities of the data.

\section{Granger Causality Results}

Table 1 presents the Granger causality results for net migration by state employment and other U.S. employment. In eight of the ten states, there is a finding of Granger causality from state employment to net migration at the 5\% significance level. The direction of this effect is best examined by the signs of the impulse responses, since the coefficients on successive lags often have changing signs, and cross-equation feedback effects can be complicated. Examination of the impulse responses reveals that the direction of the effect is positive, as expected, in all cases. 
TABLE 1

Summary of Results of Granger-Causality Tests

\begin{tabular}{|c|c|c|c|c|c|c|}
\hline & \multicolumn{4}{|c|}{ Net Migration By: } & \multirow{2}{*}{\multicolumn{2}{|c|}{$\begin{array}{l}\text { State Employment By } \\
\text { Net Migration }\end{array}$}} \\
\hline & \multicolumn{2}{|c|}{ Other U.S. Employment } & \multicolumn{2}{|c|}{ State Employment } & & \\
\hline & Chi-sq. & Prob. & Chi-sq. & Prob. & Chi-sq. & Prob. \\
\hline California (2) & 3.77 & .152 & 8.95 & $.011 *$ & .69 & .707 \\
\hline Colorado (2) & 5.91 & .052 & 17.63 & $.000 *$ & .31 & .854 \\
\hline New Hampshire (1) & 2.50 & .113 & 5.04 & $.025 *$ & 1.35 & .245 \\
\hline Washington (2) & 5.25 & .073 & 11.38 & $.003 *$ & 2.96 & .227 \\
\hline Kansas (3) & 1.66 & .645 & 7.89 & $.048 *$ & .72 & .869 \\
\hline Nebraska (2) & 9.21 & $.010 *$ & 5.84 & .054 & 1.57 & .456 \\
\hline Maryland (2) & 3.08 & .215 & 4.65 & .097 & 4.10 & .129 \\
\hline Tennessee (3) & 13.00 & $.005 *$ & 9.81 & $.023 *$ & 14.98 & $.002 *$ \\
\hline Illinois (1) & 6.02 & $.014 *$ & 4.53 & $.033 *$ & .25 & .615 \\
\hline New York (3) & 27.88 & $.000 *$ & 37.52 & $.000 *$ & 1.96 & .581 \\
\hline
\end{tabular}

Note: The causality test statistic follows a Chi-square distribution with either 1,2 , or 3 d.f. (depending upon the number of restrictions, in this case, the number of lags of each variable). The number of lags is indicated in parentheses following the state name. The null hypothesis is that the coefficients of the lagged values of the variable in the column are jointly equal to zero. Prob. is the probability of obtaining a Chi-square statistic at least as large as the test statistic under the null hypothesis. A probability level smaller than 0.05 (shown by an asterik) indicates rejection of the null hypothesis at the $5 \%$ significance level.

Table 1 also presents the Granger causality results for state employment by net migration. Net migration is not found to cause (in a Granger sense) employment in any of the states, except for Tennessee (i.e., feedback exists in Tennessee). Since Granger-causality results suggest lag/lead relationships between variables, the results suggest that employment change occurs first, followed by net migration. ${ }^{10}$

The correlation between the error terms of the different equations is a measure of instantaneous causality. The correlations between the error terms of net migration and employment for the VAR models are presented in Table 2. There is a high positive correlation (coefficient greater than .2 ) between net migration and employment in five states. In these states, it is conceivable that net migration is impacting employment within a single time period. ${ }^{11}$

\section{Intermediate-Run Multiplier Results}

Table 3 presents the intermediate-run multiplier effects of a change in state employment on net migration. ${ }^{12}$ In eight of the ten states, there is a multiplier effect over three years that is statistically different from zero, at the $5 \%$ significance level. The magnitude of the multiplier suggests that for each additional job in the 
TABLE 2

Correlation Coeffients Between the Error Terms of Net Migration and Employment Equations

\begin{tabular}{lcc}
\hline \hline & $\begin{array}{c}\text { Net Migration and } \\
\text { State Employment }\end{array}$ & $\begin{array}{c}\text { Net Migration and } \\
\text { Other U.S. Employment }\end{array}$ \\
\hline Califormia & .370 & -.176 \\
Colorado & .199 & .051 \\
New Hampshire & .291 & .317 \\
Washington & .525 & .281 \\
Kansas & .191 & -.066 \\
Nebraska & .262 & .014 \\
Maryland & -.078 & -.375 \\
Tennessee & .248 & .070 \\
Illinois & -.047 & -.120 \\
New York & -.560 & -.600 \\
\hline
\end{tabular}

state, in-migration increases by about one to two persons over a three-year period, as a state-wide average. Conversely, net migration is not found to have a multiplier effect on employment that is significantly different from zero for any of the states, either over three or six years.

Table 3 also indicates the adjustment period of migration to shocks in state employment. In seven states, net migration has a significant positive response to a change in employment with an adjustment period of two to five years. This suggests that there is a lengthy lag between employment change and net migration. A slow migration response is consistent with a micro view of migration in which households spend time seeking information on the benefits and costs of a potential move.

\section{Other Results $^{13}$}

The correlations between the errors of net migration and other U.S. employment were presented in Table 2. The two accelerating growth states (New Hampshire and Washington) show a high positive correlation, whereas two decelerating or low growth states (Maryland and New York) show a high negative correlation. The responsiveness of migrants to the business cycle may explain these signs. During times of national employment expansion, the migrant flow from low to high growth states is expected to increase. Therefore, there would be a positive association between net migration and U.S. employment in high growth states and a negative association in low growth states. 
TABLE 3

Intermediate-Run Multipliers; State Employment Effect on Net Migration

\begin{tabular}{lccc}
\hline \hline & 3 Years & 6 Years & Adjustment period \\
\hline California & $.65^{*}$ & .73 & NR \\
Colorado & $(.27)$ & $(.53)$ & \\
& $1.68^{*}$ & 1.92 & 2 \\
New Hampshire & $(.58)$ & $(1.26)$ & \\
& $.95^{*}$ & 1.62 & 3 \\
Washington & $(.42)$ & $(.82)$ & \\
& $2.27^{*}$ & 2.62 & 3 \\
Kansas & $(.66)$ & $(1.35)$ & \\
& $1.06^{*}$ & $2.29 *$ & 5 \\
Nebraska & $(.53)$ & $(1.02)$ & \\
& $1.69 *$ & 1.60 & 2 \\
Maryland & $(.71)$ & $(1.29)$ & \\
& .73 & 1.01 & \\
Tennessee & $(.38)$ & $(.59)$ & 2 \\
& $1.13^{*}$ & $2.02 *$ & \\
Illinois & $(.42)$ & $(.92)$ & NR \\
& .94 & 1.21 & \\
New York & $(.48)$ & $(.75)$ & \\
& $1.58^{*}$ & $2.50 *$ & $(.91)$ \\
\hline
\end{tabular}

Note: These intermediate-run multipliers reflect the change (over 3 or 6 years) in net migration from a one-unit increase in state employment. Standard errors are shown in parentheses. An asterisk reflects a multiplier that is greater than two standard errors.

The adjustment period is defined as the last year in which net migration has an impulse response (to a change in state employment in year 1) that is significantly different from zero, i.e. greater than two standard errors. NR indicates no such response. The direction of the net migration response is positive for all states

The Granger causality results show a similar relation. In fact, at the $10 \%$ significance level, in six states, other U.S. employment causes net migration (Table 1). The direction of the effect is positive in the high or accelerating growth states (Colorado and Washington) and negative in the medium, decelerating, or low growth states (Nebraska, Tennessee, Illinois, and New York). This evidence supports empirical findings of Greenwood, Hunt, and McDowell (1986) and Gordon (1985) that net migration is pro-cyclical. 


\section{Further Analysis and Interpretation}

To evaluate the plausibility of the model, the magnitudes obtained here are compared to those found by Greenwood and Hunt (1984). This comparison can only be done in a crude way, due to the differences between the two studies. One crucial difference is that Greenwood and Hunt used a measure of labor force migration, rather than population migration. ${ }^{14}$

Greenwood and Hunt (1984) found that 100 new jobs attract, on average, between 40 and 50 employed net in-migrants. This research finds that 100 new jobs attract an average of between 100 and 200 net in-migrants (employed persons, unemployed, and those not in the labor force). If a population-to-employment ratio of 2.5 among the in-migrants is assumed, the results appear consistent. This ratio is representative of the study states in 1985 .

Greenwood and Hunt found that, in the majority of labor market areas, another employed net in-migrant gives rise to one additional job. An equivalent result using population migration (assuming a population-to- employment ratio of 2.5 to 1 ) is that each additional in-migrant is associated with .4 jobs. For all states, the $95 \%$ confidence interval for the value of the intermediate-run multiplier of the effect of migration on employment includes both 0 and .4, so that neither value can be considered implausible.

The qualitative findings are consistent among the states (with the possible exception of Tennessee). However, there are variations among the states in the magnitude and speed by which net migration responds to employment change. Cross-section factors not incorporated in the time series model may explain such variations, including differences in non-tradeable goods among the states. States gaining population because of their attractive package of non-tradeable goods would be expected to show a weaker link from employment change to net migration. Other factors might include the demographic and socioeconomic composition of the population (e.g., responsiveness may be higher for those states with a concentration of young, highly educated persons), the industrial structure of employment, welfare and tax laws, and the provision of local public goods.

\section{SUMMARY}

The objective of this research was to enhance understanding of the relationship of net migration and regional employment over time. This study adopted a procedure that facilitates investigation of the timing of the relation. With the aid of Granger causality tests and dynamic multipliers, considerable information on the timing and speed of adjustment was obtained. The results suggest a fairly 
consistent time pattern pertaining to state-level population migration, in which state employment leads and net migration follows, with a lag. The procedure appears promising in investigating the dynamic relation of migration and employment, particularly as migration time series data become more available.

Several qualifications are in order. First, the findings are specific to the spatial unit employed, namely states. Second, the measure of net migration used in this study is aggregated over migrant characteristics and motivation for moving. Yet, behavior of migration streams may vary. For example, a stream of young and highly educated migrants would be expected to respond more quickly and with larger magnitude to employment change (compared to the aggregate migrant stream). On the other hand, some migrant streams (e.g., elderly persons) consume local services heavily and thus may impact local employment. Such relationships may only be discernible with disaggregated data.

\section{ENDNOTES}

1. First, this description can easily be stated in terms of out-migration, rather than in-migration. Second, Greenwood and Hunt (1984) outline other mechanisms by which migrants might affect the regional demand for labor.

2. If particular assumptions are made regarding the elasticities of regional labor demand and supply, the sequence of events can be established. Under the Borts and Stein (1964) view, migration does not respond to employment change. Under the Blanco, Lowry and Mazek view [as attributed by Muth (1971)], employment does not respond to migration. For more discussion of these perspectives, see Muth (1971) and Mazek and Chang (1972).

3. VAR models have been adopted in a variety of regional contexts, including applications to regional modeling [Kinal and Ratner (1986)], regional labor markets [Lesage and Magura (1986)], economic-base linkages [Mayo and Flynn (1989)], and the regional effect of oil-price shocks [Bohara (1988)]. For a critique of causality testing and VAR modeling, see Cooley and LeRoy (1983).

4. The limited degrees of freedom and data availability necessitate a simple model. It would be desirable to include other labor market variables, such as labor force participation, in the model. Preliminary attempts to add labor force participation as a fifth variable resulted in estimated models that were explosive over time, probably due to overparameterization.

5. The Granger test of causality (described below) may be sensitive to specification of lag length. Econometricians have suggested several criteria to select the proper number of lags. There is not a consensus on the preferred criterion in a small sample, since econometric theory is able to determine only the 
asymptotic properties of the estimators. The cost of underfitting a VAR model, which biases hypothesis tests, is generally thought to be greater than the cost of overfitting, which produces increased variance. Shibata (1976) demonstrated that the AIC reduces the probability of selecting too small an order in a small sample.

6. As Bessler (1984) explains, simulating the response of variables in the VAR to shocks in particular error terms is misleading if the data show a contemporaneous correlation among error terms in each series. Accordingly, an orthogonalizing transformation of the error vector is performed so that the covariance of the transformed errors will be an identity matrix. Following the VAR model in equation (1), a $\mathrm{G}$ matrix is sought, such that $\mathrm{e}=\mathrm{Gu}$ has a variancecovariance matrix equal to the identity $I$. The usual way to select $G$ is to apply a Choleski decomposition to the untransformed variance-covariance matrix $(\Sigma) . \Sigma$ is factored so that $\left(G^{-1}\right)^{\prime}\left(G^{-1}\right)=\Sigma$, where $G^{-1}$ is a lower triangular matrix. This diagonalization removes any contemporaneous correlation among series errors. The VAR model is then transformed by pre-multiplying each term by the $G$ matrix [for further detail, see Bessler (1984)].

7. To determine the standard errors of the impulse responses, a monte-carlo procedure developed by Kloek and Van Dijk (1978) and programmed by Doan and Litterman (1987) is employed. The monte-carlo procedure is adjusted to determine the standard error of the intermediate-run multipliers.

8. Although many migration studies have used data from states, provinces, or individual countries, a smaller geographical area would be preferred. There is likely more heterogeneity in the labor market conditions of states than in smaller geographical areas, such as SMSA's. However, use of state data does offer an advantage. Since this study uses population migration, it is desirable to identify a migration stream that entails changed employment (and not simply changes in housing). Change in employment generally is required for relocation across state boundaries.

9. The lack of state-wide price indices on an annual basis for the study period precludes the use of relative real wage in the VAR model. The poor quality of time series data on U.S. migration is discussed in Isserman, Plane, and McMillen (1982). More detailed information on data sources and construction is available from the authors.

10. Altemative lag-length specifications were tested to examine the sensitivity of the Granger causality results for net migration and state employment. In general, the Granger causality results were qualitatively the same for specifications with one-year longer lag lengths (than those reported in Table 1). However, shortening the lag length resulted in a finding of no relationship between net migration and employment change in some states. The VAR model may be un- 
derfitted in these specifications leading to biased Granger causality tests. These results are available from the authors.

11. There is some evidence of asymmetry in these results. There are negative correlations between the error terms of net migration and state employment for some of the decelerating and low growth states. Perhaps net migration remains constant, or even increases, during the initial period of employment decline. Not until employment declines have persisted, or from the household view until a threshold of economic discomfort is reached, does out-migration occur.

12. Examination of the impulse responses for all states revealed no instance of a statistically significant impulse response at period six or later. Also computation of nine-period multipliers for some states produced multipliers similar in magnitude to the six-period multipliers. This suggests that the adjustment process was largely completed by period six. Therefore, it was not necessary to calculate either intermediate-run multipliers of longer duration (e.g., nine or twelve years) or long-run multipliers (i.e., intermediate-run multipliers as the time period approaches infinity).

13. The results on the relation of relative wages and net migration indicate two cases in which relative wages cause (in a Granger sense) net migration. Net migration does not cause (in a Granger sense) relative wages in any states. In the high growth states of California and Colorado, relative wages have a (positive) statistically significant multiplier effect on net migration at the $5 \%$ significance level.

14. Greenwood and Hunt measured the relation over metropolitan areas, rather than states. Greenwood and Hunt defined the magnitudes of responses by the structural parameters, rather than by dynamic multipliers. The dynamic multipliers take into account the interactions of variables within the model. Also, Greenwood and Hunt measured the magnitudes at a briefer interval, since at most, one lag of annual values are included in their model.

\section{REFERENCES}

Bessler, David A. "An Analysis of Dynamic Economic Relationships: An Application to the U.S. Hog Market." Canadian Journal of Agricultural Economics. 32 (1984). 109-124.

Bohara, Alok K. "An Analysis of Oil Price Shocks on the Colorado Economy Using Vector Autoregression." The Review of Regional Studies. 18 (1988). 23-30. 
Borts, G.H. and J.L. Stein. Economic Growth in a Free Market. New York: Columbia University Press, 1964.

Brorsen, B. Wade, Jean-Paul Chavas, and Warren R. Grant. "A Dynamic Analysis of Prices in the U.S. Rice Marketing Channel." Journal of Business and Economic Statistics. 3 (1985). 362-69.

Cooley, Thomas F. and Stephen F. LeRoy. "Atheoretical Macroeconomics: A Critique." manuscript, 1983.

Doan, Thomas A. and Robert B. Litterman. "User's Manual - RATS, Version 2.11." Evanston, IL: VAR Econometrics, 1987.

Gordon, Ian. "The Cyclical Interaction Between Regional Migration, Employment, and Unemployment." Scottish Journal of Political Economy. 32 (1985). 135-58.

Granger, C.W.J. "Investigating Causal Relations by Econometric Models and Cross-Spectral Methods." Econometrica. 37 (1969). 424-438.

Graves, Phillip E. and Peter D. Linneman. "Household Migration: Theoretical and Empirical Results." Journal of Urban Economics. 6 (1979). 263-79.

Greenwood, Michael J. "Human Migration: Theory, Models, and Empirical Studies." Journal of Regional Science. (1985). 521-43.

Greenwood, Michael J. and Gary L. Hunt. "Migration and Interregional Employment Distribution in the United States." American Economic Review. (1984). 957-69.

Greenwood, Michael J., Gary L. Hunt, and John M. McDowell. "Migration and Employment Change: Empirical Evidence on the Spatial and Temporal Dimensions of the Linkage." Journal of Regional Science. 26 (1986). 223-234.

Guilkey, David K. and Michael K. Salemi. "Small Sample Properties of Three Tests for Granger-Causal Ordering in a Bivariate Stochastic System." Review of Economics and Statistics. 64 (1982). 668-679.

Isserman, Andrew M., David A. Plane, and David B. McMillen. "Internal Migration in U.S.: An Evaluation of Federal Data." Review of Public Data Use. 10 (1982). 283-309.

Kinal, Terrence and Jonathan Ratner. "A VAR Forecasting Model of a Regional Economy: Its Construction and Comparative Accuracy." International Regional Science Review. 10 (1986). 113-126.

Kloek, T. and H.K. Van Dijk. "Bayesian Estimates of Equation System Parameters: An Apllication of Integration by Monte Carlo." Econometrica. 46 (1978). 1-20.

Lesage, James P. and Michael Magura. "Econometric Modeling of Interregional Labor Market Linkages." Journal of Regional Science. 26 (1986). 567-577. 
Mayo, John W. and Joseph E. Flynn. "Firm Entry and Exit: Causality Tests and Economic-Base Linkages." Journal of Regional Science. 29 (1989). 645-662.

Mazek, W.F. and J. Chang. "The Chicken or Egg Fowl-Up in Migration: Comment." Southern Economic Journal. 39 (1972). 133-39.

Molho, Ian. "A Dynamic Model of Interregional Migration Flows in Great Britain." Journal of Regional Science. 24 (1984). 317-37.

Muth, Richard F. "Migration: Chicken or Egg?" Southern Economic Journal. 37 (1971). 295-306.

Neftci, S. N. "A Time Series Analysis of the Real Wages-Employment Relationship." Journal of Political Economy. 86 (1978). 281-291.

Rogerson, Peter A. and David A. Plane. "Monitoring Migration Trends." American Demographics. 7 (1985). 27-29, 47.

Sargent, Thomas J. "A Classical Macroeconomic Model for the United States." Journal of Political Economy. 84 (1976). 207-237.

Schmitz, Gary Earl. "A Time Series Investigation into the Causes of Regional Economic Growth." Ph.D. dissertation, Department of Economics, University of Colorado at Boulder, 1986.

Shibata, R. "Selections of the Order of an ARMA Model by Akaikes's Information Criterion." Biometrika. 61 (1976). 117-26.

Sims, Christopher A. "Macroeconomics and Reality." Econometrica. 48 (1980). $1-48$.

Sjaastad, L. "The Costs and Returns of Human Migration." Journal of Political Economy. 70 (1962). 80-93.

U.S. Bureau of the Census (1988), Statistical Abstract of the United States, 1988 (108th edition), Table 21, 18, xvii.

U.S. Bureau of the Census (1989), Statistical Abstract of the United States, 1989 (109th edition), Table 656. 